Journal of Engineering and Applied Sciences 14 (9): 3063-3071, 2019

ISSN: 1816-949X

(C) Medwell Journals, 2019

\title{
A Proposed Methodology for Reducing Cost and Time When Transforming to a (I-MR) Chart and Design Worker Control Chart
}

\author{
Ahmed Abdul Rasool Ahmed Al-Kafaji \\ Department of Mechanical Engineering, College of Engineering, University of Baghdad, Baghdad, Iraq
}

\begin{abstract}
The quality control charts are one of the most important tools in controlling statistical quality. It is a cost added to the product. There are many different control charts, the most widely used are the variable control charts. These charts depend on the size of the sample. The larger the sample size the greater the accuracy and cost. The cost increases when destructive testing is implemented. The aim of the research is to propose a methodology to benefit from previous data, to improve accuracy and reduce costs. The methodology has been applied for a 25 samples, each of them a 5 sized sample. The average was calculated based on samples of different sizes (2-5), its average values are considered as the single sample applied in (I-MR) chart. The calculations and the control chart drawing were performed by the Software "Minitab". This research also studied the process capability results that were obtained by the proposed methodology as well as their indicators. The number of trails to achieve the accredited control limits for the succeeding application for characteristic understudy was reduced. The value of standard deviation decreases when the sample size increases. The process capability, also, increased with the increase in the size of the sample. The calculated mean process shifted from the target mean towards its USL for all sample sizes under study. The proposed methodology shows that the switch to (I-MR) chart is easy and can be easily applied by the workers. It is necessary to state the values of the last sample, from which the control limits were found which is considered to be the previous sample which calculates the moving average of the first sample of the application.
\end{abstract}

Key words: I-MR chart, SPC, process capability, size, accuracy, indicators

\section{INTRODUCTION}

The quality control charts of different types are the important sstatistical tools used in controlling the quality of the production as well as in the analysis of the productive process. (Xbar-R) charts are the most used charts in the control of the statistical process. These charts have been applied to many products and services and have given good results for easy calculation and easy application by workers. The main task in selecting the control limits of the production process is the duty of the men controlling the quality, these limits are considered to be basic tasks. The nature of the problem as well as the precision of the intended characteristic to be controlled. A large number of researchers have worked on the development of these charts. Most of the application processes take at least two samples in determining the approved control limits. For the purpose of increasing accuracy, more than that may be added up to the sample size of five or more. The purpose of this research is to define the limits of the control of the (Xbar-R) chart previously applied by the (I-MR) chart, that need to single out one by taking advantage of previously aggregated data. Minitab Software applies to the drawing and calculations for these types of control charts.

Li et al. (2007) suggests for individual observation using moving range charts which is applied to estimate the actual time when a step change has taken place in process variances. The results indicate that it helps engineers to identify the special causes in time and enables the production process to return to normal, so, the proposed change point estimator is easily implement to improve production efficiency.

Hill et al. (2007) established a simple and practical technique that has proved successful in identifying such components while minimizing false alarm in the electronic industry, involving high volume components introduce moving difference charts has led to greater consistency and quantifiable rules, the results show this chart suggest giving useful dynamic indications of output.

Aliverdi et al. (2013) described the (I-MR) charts for monitor measurement of project time and cost performance indices of a real construction project were monitored regularly on the individual chart by using 
Minitab Software. The results were quiet promising and not only completed well against traditional approaches at the end it was concluded that the proposed approach improves the project controlling scheme and enhances the capability of earned value.

Doshi and Darshak (2016) introduced statistical process control tools to study for automotive SMEs and to measure its impact on continuous quality (Xbar-R) chart is one of the important tools to examine and monitor a process variation and provide the means to improve process continuously based on numerical analysis. After implementation of proper action process capability, improved significantly in all companies.

Theortical of the I-MR chart and process capability: This chart, like other control charts, consists of two charts of the average chart to control the properties of the center and its knowledge of the amount of shifting from the target value. And a moving range board to determine the amount of dispersion characteristic. These control charts are used for subgroups consisting of a single numerical measurement. The I-chart is used for monitoring the process level and the MR-chart is used for monitoring the short-term variability.

Denote the observation, $x_{i}$ as the individual observation in the ith subgroup, $I=1,2, \ldots, k$. The moving range is defined an equation:

$$
\mathrm{MR}_{\mathrm{i}}=\left|\mathrm{x}_{\mathrm{i}}-\mathrm{x}_{\mathrm{i}-1}\right|
$$

Calculate the average individual values over all $\mathrm{k}$ subgroups and average moving ranges for $\mathrm{k}-1$ subgroup:

$$
\begin{gathered}
\overline{\mathrm{X}}=\sum_{\mathrm{i}=1}^{\mathrm{k}} \frac{\mathrm{x}_{\mathrm{i}}}{\mathrm{k}}=\left(\mathrm{x}_{1}+\mathrm{x}_{2}+, \ldots, \mathrm{x}_{\mathrm{k}}\right) / \mathrm{k} \\
\overline{\mathrm{MR}}=\sum_{\mathrm{i}=1}^{\mathrm{k}} \frac{\mathrm{MR}_{\mathrm{i}}}{\mathrm{K}-1}=\left(\mathrm{MR}_{1}+\mathrm{MR}_{2}+, \ldots, \mathrm{MR}_{\mathrm{k}}\right) /(\mathrm{K}-1)
\end{gathered}
$$

These values are used for the center lines on the control charts as for calculating the control limit, for two charts (ASTM E2587-16, 2016). Form the I-chart:

$$
\begin{aligned}
\mathrm{UCL} & =\overline{\mathrm{X}}+2.66 \overline{\mathrm{MR}} \\
\mathrm{LCL} & =\overline{\mathrm{X}}-2.66 \overline{\mathrm{MR}}
\end{aligned}
$$

For the MR-chart:

$$
\mathrm{UCL}=3.27 \overline{\mathrm{MR}}
$$

$$
\mathrm{LCL}=0
$$

An estimate of the inherent (common causes) standard deviation may be calculated.

$$
\sigma=\frac{\overline{\mathrm{MR}}}{1.128}
$$

The capability indices measure what a process would be capable of if it were stable. The performance indices measure the current performance of the process, regardless of, whether, it is stable or not (Joglekar, 2003). Four basic indices are used to measure process capability. They are as following's index capability indices that qualify process potential and process performance are practical tools for successful quality improvement activities and quality program implementation. This index can be illustrated in Eq. 9 (Sun et al., 2010):

$$
\mathrm{Cp}=\frac{\mathrm{USL}-\mathrm{LSL}}{6 \sigma}
$$

Where:

USL and LSL = Upper and Lower Specification Limit

$\sigma \quad=$ Standard deviation of the process

The six quality conditions and the corresponding $\mathrm{Cp}$ value are summarized in Table 1 (Kaya and Kahraman, 2008). Cpk describes how well the process fits within the specificity limits as demonstrated in the following equations (Rezaie et al., 2006):

$$
\mathrm{Cpk}=\frac{\min (\mathrm{USL}-\mu, \mu-\mathrm{LSL})}{3 \sigma}
$$

where, $\mu=$ Process mean

$$
\text { Or Cpk }=\frac{\min (\mathrm{Cpu}, \mathrm{Cpl})}{3 \sigma}
$$

Where:

$$
\mathrm{Cpu}=\frac{\mathrm{USL}-\mu}{3 \sigma}
$$

Table 1: Quality conditions and Cp value

\begin{tabular}{ll}
\hline Quality conditions & Cp value \\
\hline Supper excellent & $2.00 \leq \mathrm{Cp}$ \\
Excellent & $1.67 \leq \mathrm{Cp} \leq 2.00$ \\
Satisfactory & $1.33 \leq \mathrm{Cp} \leq 1.67$ \\
Capable & $1.00 \leq \mathrm{Cp} \leq 1.33$ \\
Inadequate & $0.67 \leq \mathrm{Cp} \leq 1.00$ \\
Poor & $\mathrm{Cp} \leq 0.67$ \\
\hline
\end{tabular}




$$
\begin{gathered}
\mathrm{Cpl}=\frac{\mu-\mathrm{LSL}}{3 \sigma} \\
\mathrm{Cpm}=\frac{\mathrm{USL}-\mathrm{LSL}}{6 \sqrt{\sigma^{2}+(\mu-\mathrm{T})^{2}}}
\end{gathered}
$$

where, $\sigma^{2}=$ the process variance

\section{MATERIALS AND METHODS}

Practical application: The proposed methodology is to take advantage of the previous data in determining the limits of the control of the implementation of the I-MR charts. Table 2 shows the combined data of 25 items, sample size five of a product manufacturing by $\mathrm{CNC}$ lengths machine with has specified $(50 \pm 0.1 \mathrm{~mm})$, the Minitab-17 Software used for drawing and analyzing the limited control bounders charts and ability of the process capability and its indicators. Table 3 shows the calculations for the average for each sample at the size of (2-5), respectively. By using Eq. 2.

The results of the application of the Eq. 1 and 3 are shown in Table 4. Each column in table shows the calculation of the moving range for each sample by applying Eq. 1. The last row of the table shows the average range by applying Eq. 3. Table 5 shows the limits

Table 2: Measured characteristics data of the sample diameter of spray

\begin{tabular}{|c|c|c|c|c|c|}
\hline \multirow[b]{2}{*}{ Sample No. } & \multicolumn{5}{|c|}{ Sample size } \\
\hline & $\mathrm{X}_{1}$ & $\mathrm{X}_{2}$ & $X_{3}$ & $X_{4}$ & $\mathrm{X}_{5}$ \\
\hline 1 & 50.10 & 49.95 & 50.00 & 50.10 & 50.00 \\
\hline 2 & 50.98 & 50.00 & 49.90 & 50.01 & 50.01 \\
\hline 3 & 49.92 & 49.92 & 50.00 & 50.08 & 50.06 \\
\hline 4 & 50.00 & 50.06 & 50.07 & 50.10 & 50.05 \\
\hline 5 & 50.04 & 50.04 & 50.09 & 50.08 & 50.05 \\
\hline 6 & 50.08 & 50.02 & 49.92 & 49.92 & 49.90 \\
\hline 7 & 49.90 & 49.95 & 49.96 & 50.00 & 50.00 \\
\hline 8 & 50.00 & 50.00 & 50.04 & 50.04 & 49.96 \\
\hline 9 & 49.99 & 49.98 & 50.05 & 50.06 & 50.06 \\
\hline 10 & 50.01 & 50.02 & 50.02 & 50.06 & 49.94 \\
\hline 11 & 50.00 & 50.00 & 50.01 & 49.98 & 49.98 \\
\hline 12 & 49.95 & 49.98 & 49.97 & 49.97 & 50.05 \\
\hline 13 & 50.04 & 50.04 & 50.10 & 50.05 & 50.05 \\
\hline 14 & 50.09 & 50.09 & 50.05 & 50.05 & 49.98 \\
\hline 15 & 50.00 & 50.00 & 50.05 & 50.08 & 50.09 \\
\hline 16 & 50.09 & 50.06 & 50.02 & 49.98 & 49.98 \\
\hline 17 & 50.06 & 50.03 & 50.03 & 50.01 & 49.98 \\
\hline 18 & 49.98 & 49.98 & 49.97 & 49.96 & 50.01 \\
\hline 19 & 50.09 & 50.08 & 50.09 & 50.00 & 50.00 \\
\hline 20 & 50.10 & 50.10 & 50.04 & 49.99 & 49.98 \\
\hline 21 & 50.09 & 50.09 & 50.00 & 49.98 & 49.97 \\
\hline 22 & 49.92 & 49.90 & 49.99 & 50.00 & 50.00 \\
\hline 23 & 50.04 & 50.05 & 50.00 & 50.00 & 49.97 \\
\hline 24 & 49.96 & 49.99 & 49.99 & 50.01 & 50.04 \\
\hline 25 & 50.09 & 50.09 & 50.05 & 50.05 & 49.98 \\
\hline
\end{tabular}
irrigation water made from copper of the control applied at the size of different samples by applying Eq. 4-7 as well as the number of attempts to reach these limits in the medium and moving charts. Figure 1-8 are shown the average and the moving range charts of samples of size $2-5$, respectively.

Table 3: The calculated results of the sample average according to their size Mean at:

\begin{tabular}{lcccc} 
& $\mathrm{n}$ & $\mathrm{n}=2$ & $\mathrm{n}=4$ & $\mathrm{n}=5$ \\
\hline 1 & 50.0250 & 50.0167 & 50.0375 & 50.030 \\
2 & 50.4900 & 50.2933 & 50.2225 & 50.180 \\
3 & 49.9200 & 49.9467 & 49.9800 & 49.996 \\
4 & 50.0300 & 50.0433 & 50.0575 & 50.056 \\
5 & 50.0400 & 50.0567 & 50.0625 & 50.060 \\
6 & 50.0500 & 50.0067 & 49.9850 & 49.968 \\
7 & 49.9250 & 49.9367 & 49.9525 & 49.962 \\
8 & 50.0000 & 50.0133 & 50.0200 & 50.008 \\
9 & 49.9850 & 50.0067 & 50.0200 & 50.028 \\
10 & 50.0150 & 50.0167 & 50.0275 & 50.010 \\
11 & 50.0000 & 50.0033 & 49.9975 & 49.994 \\
12 & 49.9650 & 49.9667 & 49.9675 & 49.984 \\
13 & 50.0400 & 50.0600 & 50.0575 & 50.056 \\
14 & 50.0900 & 50.0767 & 50.0700 & 50.052 \\
15 & 50.0000 & 50.0167 & 50.0325 & 50.044 \\
16 & 50.0750 & 50.0567 & 50.0375 & 50.026 \\
17 & 50.0450 & 50.0400 & 50.0325 & 50.022 \\
18 & 49.9800 & 49.9767 & 49.9725 & 49.980 \\
19 & 50.0850 & 50.0867 & 50.0650 & 50.052 \\
20 & 50.1000 & 50.0800 & 50.0575 & 50.042 \\
21 & 50.0900 & 50.0600 & 50.0400 & 50.026 \\
22 & 49.9100 & 49.9367 & 49.9525 & 49.962 \\
23 & 50.0450 & 50.0300 & 50.0225 & 50.012 \\
24 & 49.9750 & 49.9800 & 49.9875 & 49.998 \\
25 & 50.0900 & 50.0767 & 50.0700 & 50.052 \\
\hline & & & &
\end{tabular}

Table 4: The calculated results of the moving range of samples depending

\begin{tabular}{|c|c|c|c|c|}
\hline \multirow[b]{2}{*}{$\underline{\mathrm{k}}$} & \multicolumn{4}{|l|}{ MR at: } \\
\hline & $\mathrm{n}=2$ & $\mathrm{n}=3$ & $\mathrm{n}=4$ & $\mathrm{n}=5$ \\
\hline 1 & - & - & - & - \\
\hline 2 & 0.465000 & 0.27660 & 0.1850 & 0.1500 \\
\hline 3 & 0.570000 & 0.34660 & 0.2425 & 0.1840 \\
\hline 4 & 0.110000 & 0.09660 & 0.0775 & 0.0600 \\
\hline 5 & 0.010000 & 0.01340 & 0.0050 & 0.0040 \\
\hline 6 & 0.010000 & 0.05000 & 0.0775 & 0.0980 \\
\hline 7 & 0.125000 & 0.07000 & 0.0325 & 0.0060 \\
\hline 8 & 0.075000 & 0.07660 & 0.0675 & 0.0460 \\
\hline 9 & 0.015000 & 0.00660 & 0.0000 & 0.0200 \\
\hline 10 & 0.030000 & 0.01000 & 0.0075 & 0.0180 \\
\hline 11 & 0.015000 & 0.01340 & 0.0600 & 0.0160 \\
\hline 12 & 0.035000 & 0.03660 & 0.0300 & 0.0100 \\
\hline 13 & 0.075000 & 0.09330 & 0.0900 & 0.0720 \\
\hline 14 & 0.050000 & 0.01670 & 0.0125 & 0.0040 \\
\hline 15 & 0.090000 & 0.06000 & 0.0375 & 0.0080 \\
\hline 16 & 0.075000 & 0.04000 & 0.0050 & 0.0180 \\
\hline 17 & 0.030000 & 0.01670 & 0.0050 & 0.0040 \\
\hline 18 & 0.065000 & 0.06330 & 0.0600 & 0.0420 \\
\hline 19 & 0.105000 & 0.11000 & 0.0925 & 0.0720 \\
\hline 20 & 0.015000 & 0.00670 & 0.0075 & 0.0200 \\
\hline 21 & 0.010000 & 0.02000 & 0.0175 & 0.0100 \\
\hline 22 & 0.180000 & 0.12330 & 0.0875 & 0.0640 \\
\hline 23 & 0.135000 & 0.09330 & 0.0700 & 0.0500 \\
\hline 24 & 0.070000 & 0.05000 & 0.0350 & 0.0140 \\
\hline 25 & 0.115000 & 0.09670 & 0.0825 & 0.0540 \\
\hline$\overline{\mathrm{MR}}$ & 0.103125 & 0.07443 & 0.0566 & 0.0431 \\
\hline
\end{tabular}
on their size 

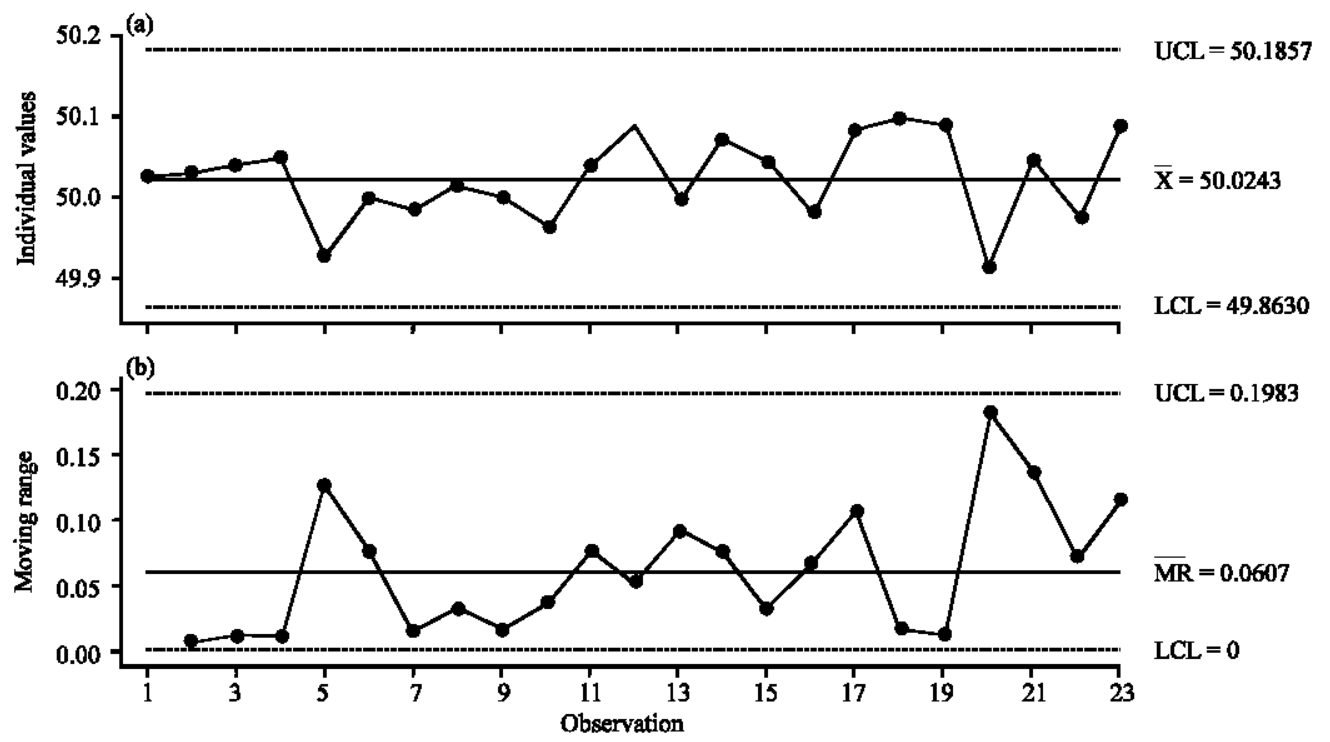

Fig. 1: a, b) Average and moving range charts at sample size 2; I-MR chart of mean
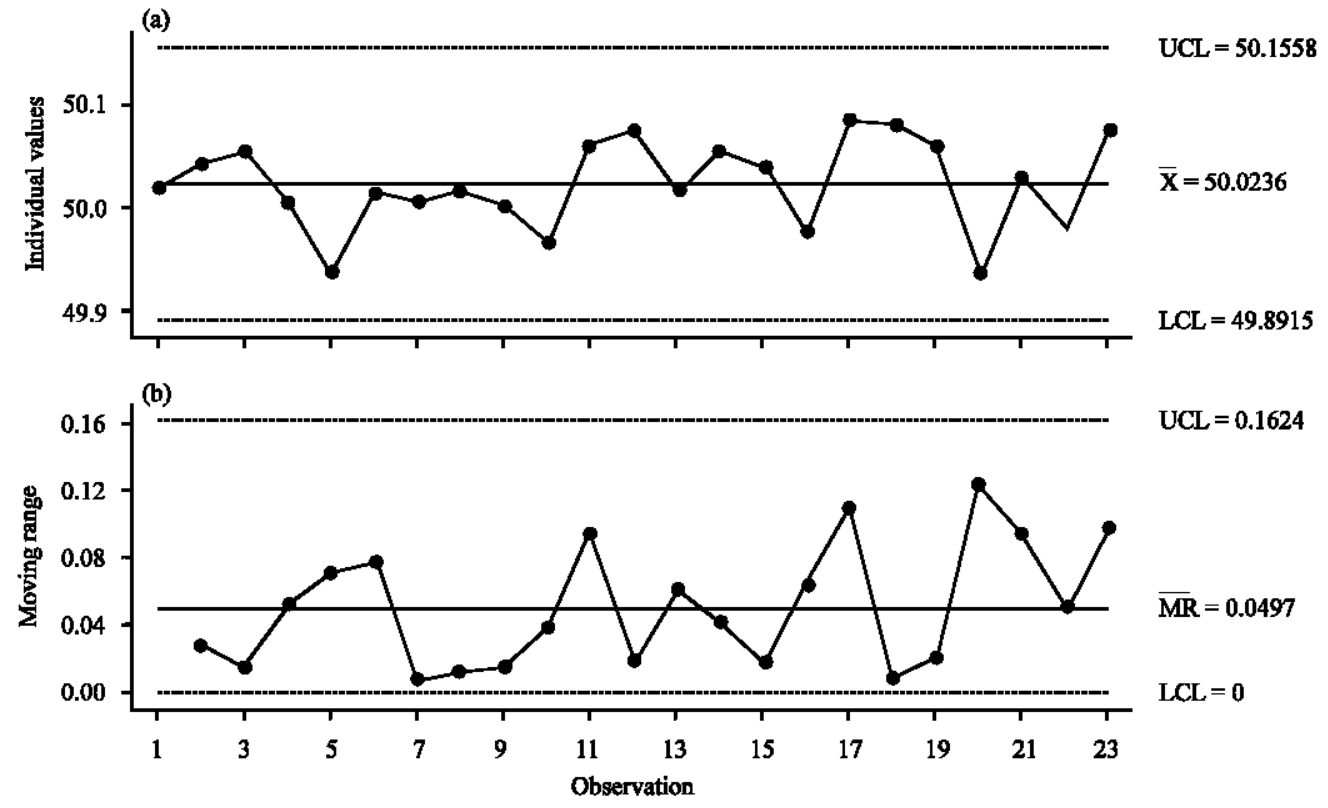

Fig. 2: a, b) Average and moving range charts at sample size 3; I-MR chart of mean

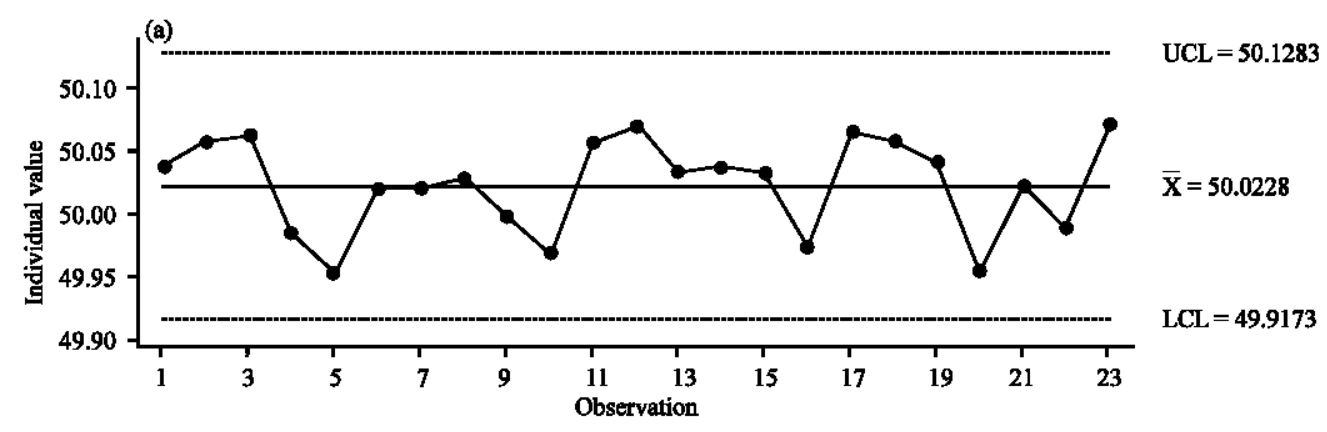

Fig. 3: Continue 


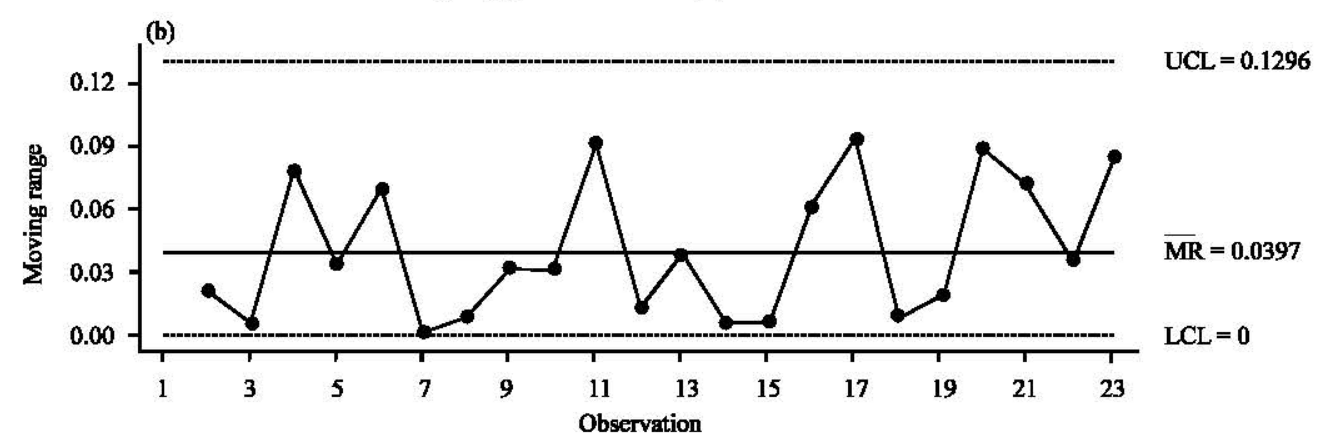

Fig. 3: a, b) Average and moving range charts at sample size 4; I-MR chart of mean
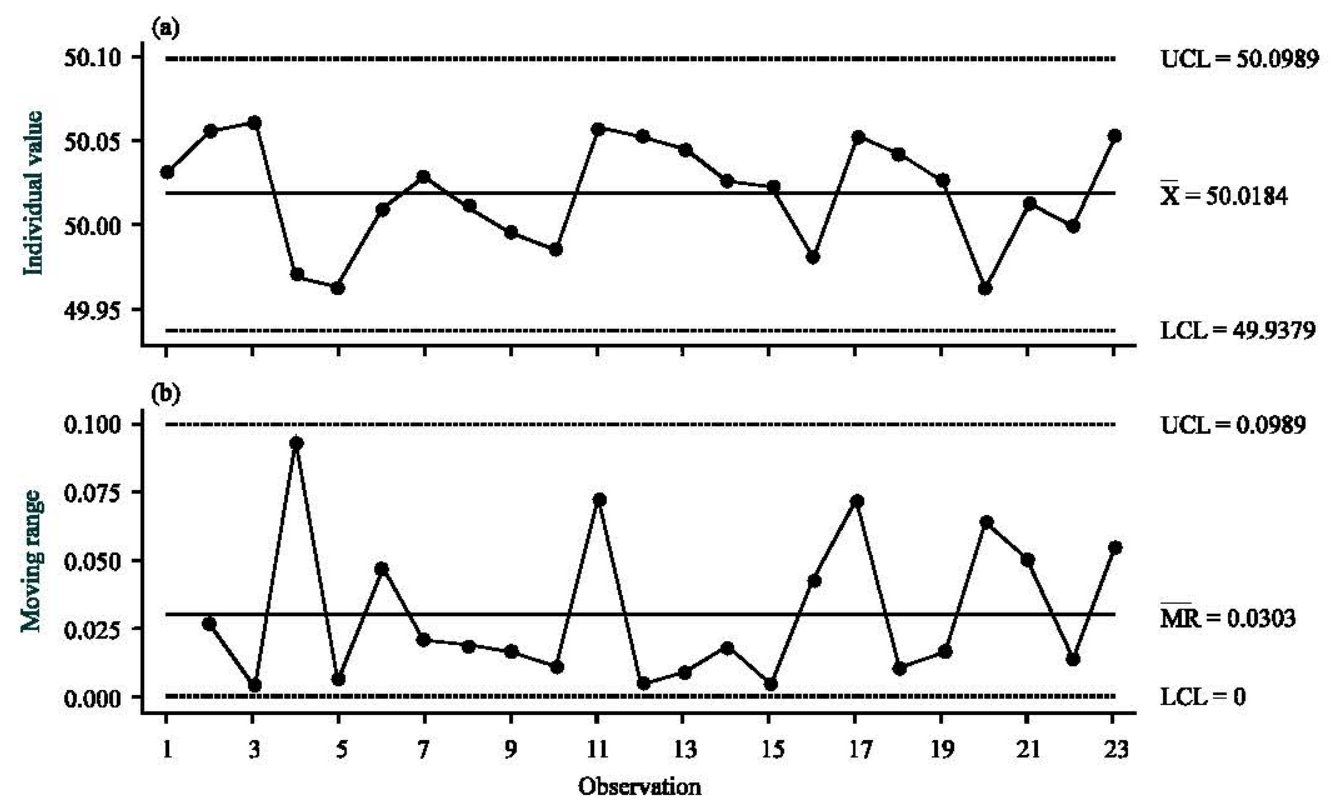

Fig. 4: a, b) Average and moving range charts at sample size 5; I-MR chart of mean

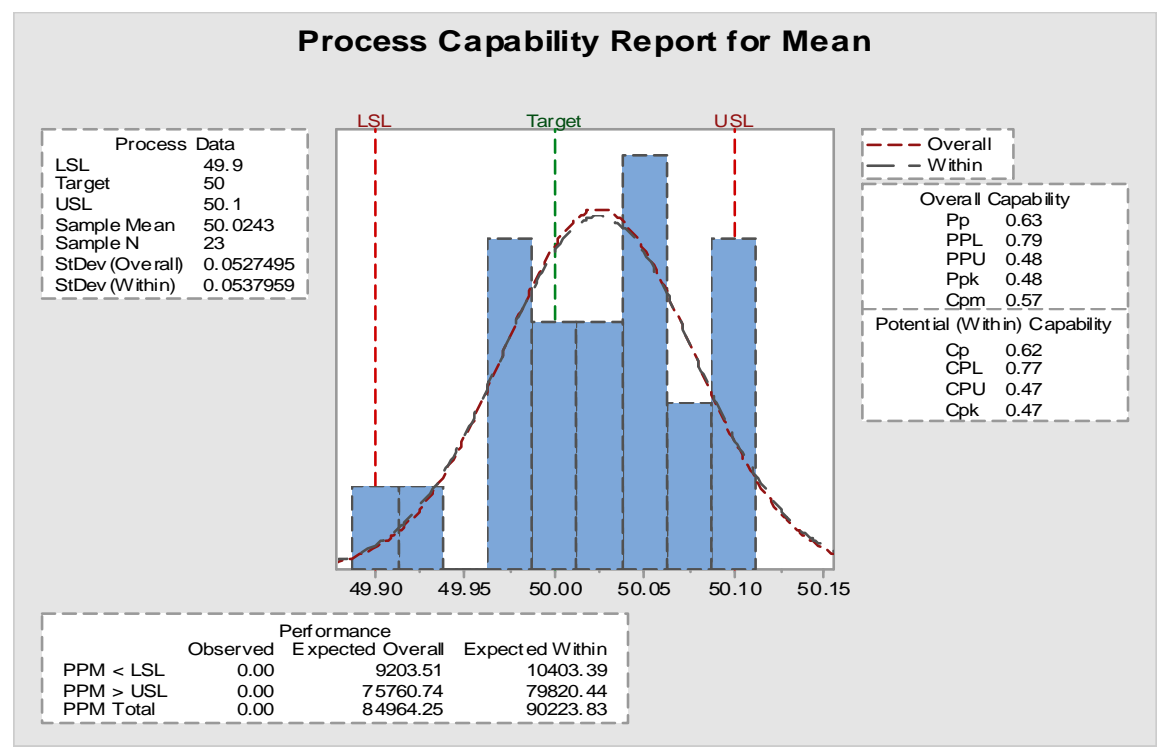

Fig. 5: Results of process capability and indicators estimated from the size of sample 2 


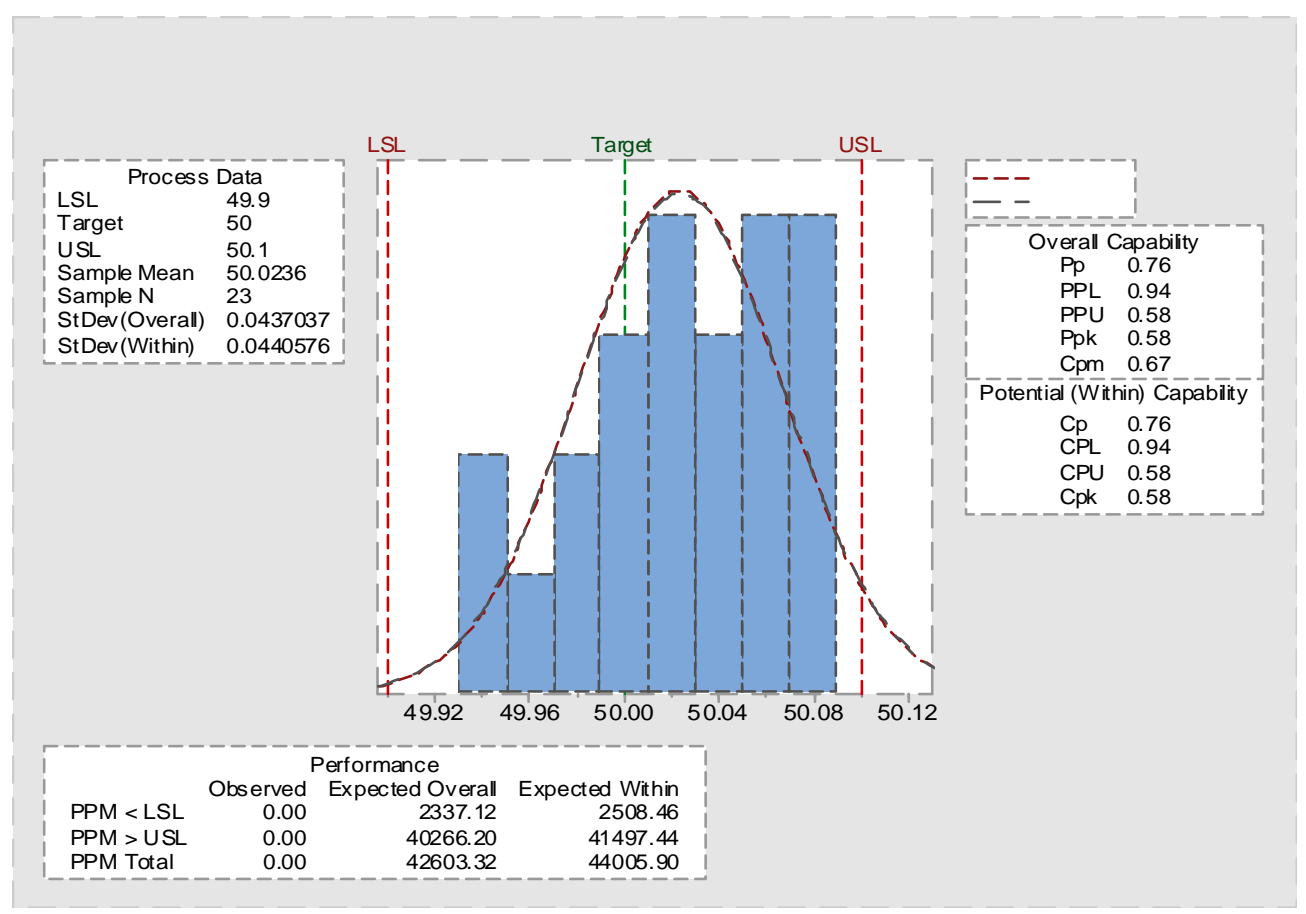

Fig. 6: Results of process capability and indicators estimated from the size of sample 3

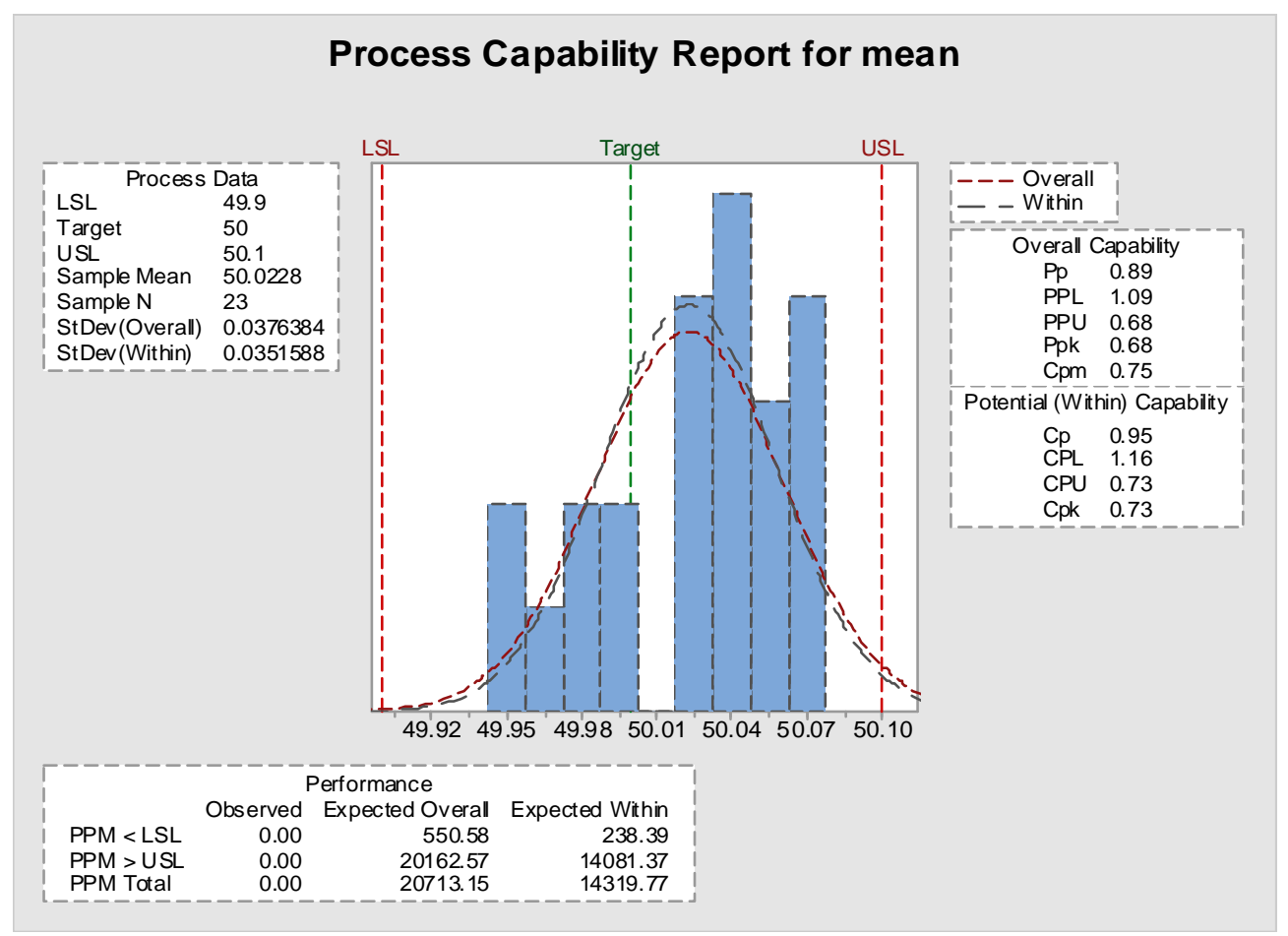

Fig. 7: Results of process capability and indicators estimated from the size of sample 4

The application of Eq. 10-14 referred to in the theoretical part of the research and using the Minitab Software, Fig. 5-8 shows process capability and indicators, the reports given by the software in different samples of size after the application of the (I-MR) chart. 


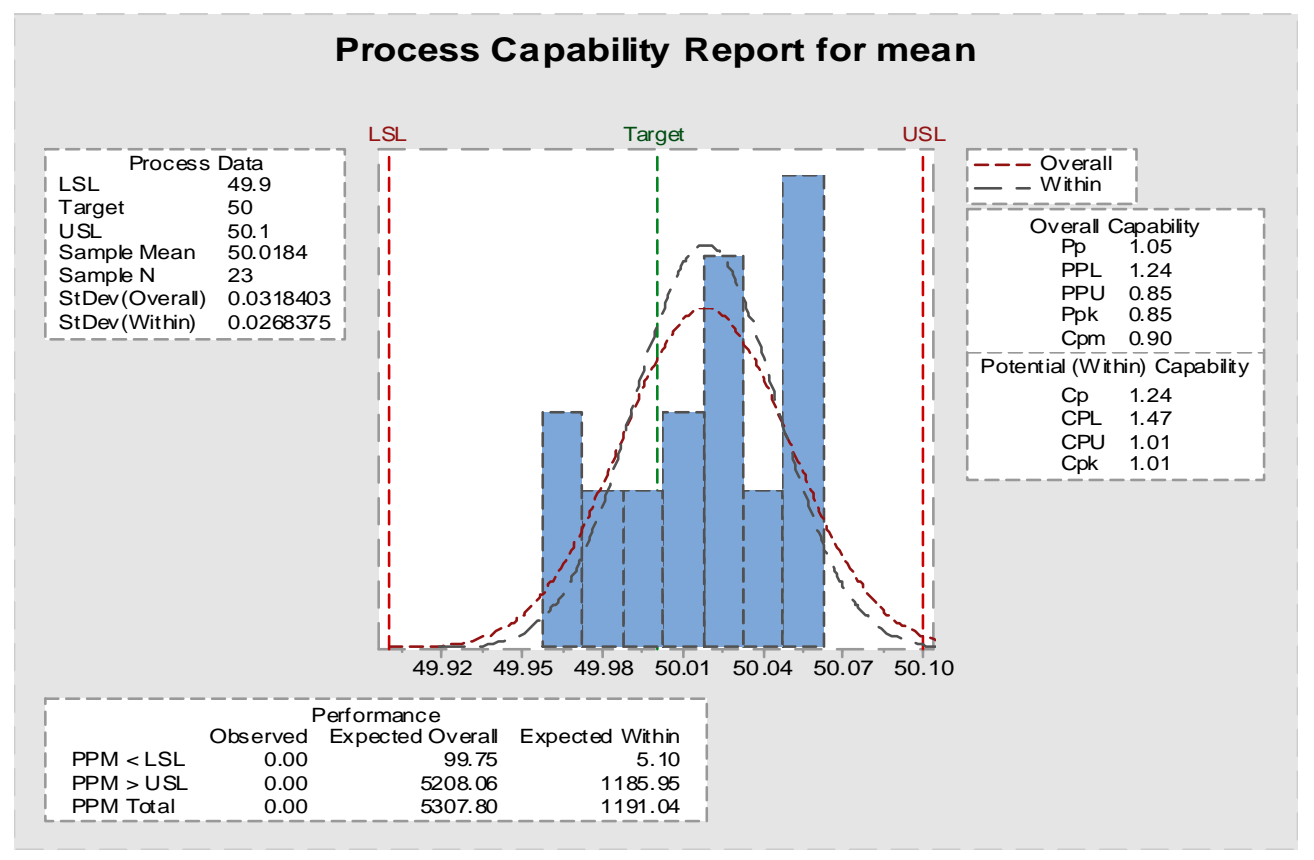

Fig. 8: Results of process capability and indicators estimated from the size of sample 5

\section{RESULTS AND DISCUSSION}

The average calculated in Table 5 show that it is shifting from the target average, towards its USL, for all sample sizes under study. The value of the displacement decreases as the size of the sample increases. In Table 5, we also notice a decrease and a standard deviation when the sample size increases.

The results of the moving range calculations are shown in Table 4 . The larger the sample size, the lower the moving range. Because it is approaching the reality of the society to which it belongs and the statistical concept to obtain accuracy. The economic aspect should reduce the size of the sample because it cost additional, special when destructive examination of the samples under study.

The approved control charts shown in Fig. 1-4 were obtained after two attempts, the number of samples remaining in the calculated mean, depends on the sample size is 23 samples. Two samples were deleted ( 2 and 3 ) in or application with different size. Control limits shrink as the sample size increases, due to the decrease standard deviation.

The results of the reports of the process capability at different sizes of samples which is shown in Table 6 and Fig. 5-8. Notice that the sample of five items was capable to achieve the limits of the specification with a value of 1.05. The samples whose size 3 and 4 were inadequate and
Table 5: The approved control limits for the medium chart and the moving range chart, depending on the size of the sample

\begin{tabular}{|c|c|c|c|c|c|c|}
\hline \multirow[b]{2}{*}{$\mathrm{n}=$} & \multicolumn{3}{|l|}{ I-chart } & \multicolumn{3}{|c|}{ MR-chart } \\
\hline & $\bar{x}$ & $\mathrm{UCL}$ & $\mathrm{LCL}$ & $\overline{\mathrm{MR}}$ & UCL & LCL \\
\hline 2 & 50.0243 & 50.1857 & 49.8630 & 0.0607 & 0.1983 & 0 \\
\hline 3 & 50.0236 & 50.1558 & 49.8915 & 0.0497 & 0.1624 & 0 \\
\hline 4 & 50.0228 & 50.1283 & 49.9173 & 0.0397 & 0.1296 & 0 \\
\hline 5 & 50.0184 & 50.0989 & 49.9379 & 0.0303 & 0.9890 & 0 \\
\hline $\mathrm{n}=$ & \multicolumn{2}{|c|}{ No. of sample } & \multicolumn{2}{|c|}{$\sigma$} & \multicolumn{2}{|c|}{ No. of trail } \\
\hline 2 & \multicolumn{2}{|c|}{23} & \multicolumn{2}{|c|}{0.0527495} & \multicolumn{2}{|r|}{2} \\
\hline 3 & \multicolumn{2}{|c|}{23} & \multicolumn{2}{|c|}{0.0437037} & \multicolumn{2}{|r|}{2} \\
\hline 4 & \multicolumn{2}{|c|}{23} & \multicolumn{2}{|c|}{0.0376384} & \multicolumn{2}{|r|}{2} \\
\hline 5 & \multicolumn{2}{|c|}{23} & \multicolumn{2}{|c|}{0.0318403} & \multicolumn{2}{|r|}{2} \\
\hline
\end{tabular}

Table 6: Results of the analysis of the estimates and indicators at different sizes of the sample

\begin{tabular}{lcccccc}
\hline $\mathrm{n}$ & $\sigma$ & Cp or PP & PPL & PPU & Cpk or Ppk & Cpm \\
\hline 2 & 0.0527495 & 0.63 & 0.79 & 0.48 & 0.48 & 0.57 \\
3 & 0.0437037 & 0.76 & 0.94 & 0.58 & 0.58 & 0.67 \\
4 & 0.0376384 & 0.89 & 1.09 & 0.68 & 0.68 & 0.75 \\
5 & 0.0318403 & 1.05 & 1.24 & 0.85 & 0.85 & 0.90 \\
\hline
\end{tabular}

the sample size 2 was poor in achieving the specification limits, according to Table 1 of the qualification requirements.

Table 7 a single sample is taken from the same production machine under study every hour produced. Table 8 values (I) and (MR) to verify the conformity of the limit controls, calculated at the different sizes of the averages of previous samples, at Table 3 . Values (I) when the application is similar to the control limits calculated in Table 8. As well as the value of the moving average of 


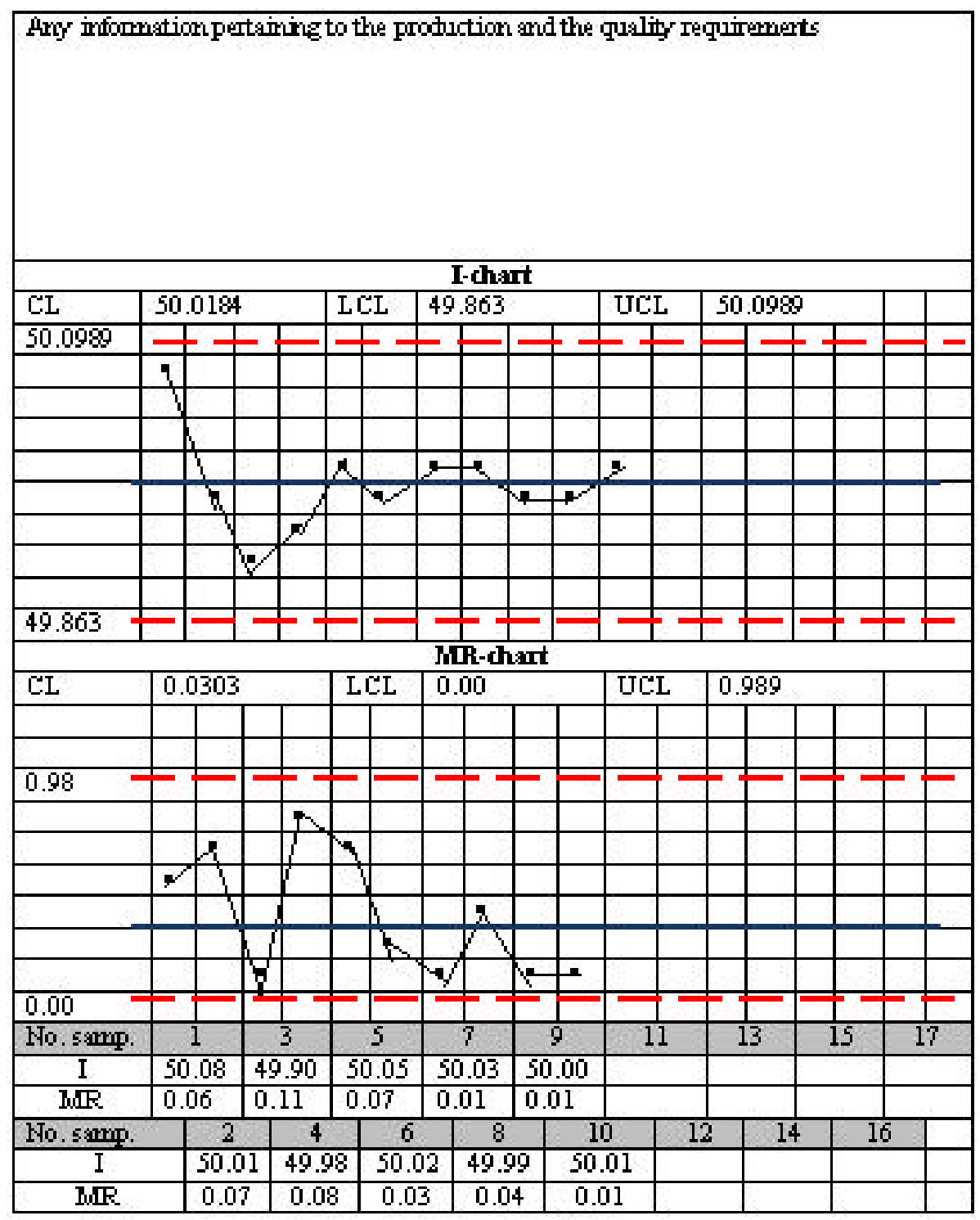

Fig. 9: The (I-MR) control chart are designed to be applied by workers in production and quality control, applied to test data collected after finding control limits of the sample size 5

Table 7: A single sample is taken from the same production machine under study every hour produced

\begin{tabular}{lc}
\hline SN & Dimension (mm) \\
\hline 1 & 50.08 \\
2 & 50.01 \\
3 & 49.90 \\
4 & 49.98 \\
5 & 50.05 \\
6 & 50.02 \\
7 & 50.03 \\
8 & 49.99 \\
9 & 50.00 \\
10 & 50.01 \\
\hline
\end{tabular}

samples, except the first sample because its value depends on its last-sample value calculated in Table 3 of
Table 8: Values (I) and (MR) to verify the conformity of the limit controls, calculated at the different sizes of the averages of previous samples The absolute value of the difference was calculated from its average values for the last sample of the Table 3

\begin{tabular}{lllll} 
Variables & $\mathrm{n}=2$ & $\mathrm{n}=3$ & $\mathrm{n}=4$ & $\mathrm{n}=5$ \\
\hline $\mathrm{MR} 1$ & 0.010 & 0.050 & 0.060 & 0.060 \\
$\mathrm{MR}_{2}-\mathrm{MR}_{10}$ except the & at $\mathrm{n}=2-5$ & 0.070 & 0.110 & $0.08,0.07$ \\
first depends on the size & 0.030 & 0.010 & 0.040 & $0.01,0.01$ \\
shown in the first row & & & & \\
$\mathrm{I}_{1}-\mathrm{I}_{10}$ & 50.08 & 50.01 & 49.90 & $49.98,50.05$ \\
& 50.02 & 50.03 & 49.99 & $50.00,50.01$ \\
\hline
\end{tabular}

All values were within the control limits of the all sample size

averages of sizes for different samples, this shows MR1 values in Table 8 . All values were within the control limits of the all sample sizes (Fig. 9). 


\section{CONCLUSION}

The shifting of the calculated mean is evidence that the process needs intense monitoring if it remained as it is. If the cause for the shifting is reset and maintained, then monitoring the operation is reduced with a reduction in costs. It is beneficial when the product exceeds the specification limit where it can be dealt with as rework and not scrap, this is achieved when there is a shift in "USL" of the characteristic under study. Thus, the cost will be reduced for the raw material.

To obtain a more precise accuracy when calculating the accredited control limits, it is preferred that the sample size is the largest when taken at the beginning. Although the cost is higher especially in destructive testing but it is more reliable for a longer period of time but is cost less for a longer period of application.

The number of attempts to obtain the accredited control limits when applying the (I-MR) chart is less than the application of control charts for other variables. This leads to a reduction of time as well as the number of deleted units, thereby reducing the recurrence of calculation in addition to a greater accuracy, due to the large number of samples remaining.

If the sample size is increased, the proposed method of converting to a single-item chart will give the best process capability and its indicator from the least sample size. The proposed methodology shows that the switch to (I-MR) chart is easy and can be easily applied by the workers. It is necessary to state the values of the last sample, from which the control limits were found which is considered to be the previous sample which calculates the moving average of the first sample of the application. It shows the (I-MR) control chart are designed to be applied by workers in production and quality control, after finding the control limits of the proposed methodology.

\section{REFERENCES}

ASTM E2587-16, 2016. Standard practice for use of control charts in statistical process control. ASTM International, West Conshohocken, Pennsylvania. https://www.astm.org/Standards/E2587.htm

Aliverdi, R., L.M. Naeni and A. Salehipour, 2013. Monitoring project duration and cost in a construction project by applying statistical quality control charts. Intl. J. Project Manage., 31: 411-423.

Doshi, J.A. and D.A. Desai, 2016. Statistical process control: An approach for continuous quality improvement in automotive SMEs-Indian case study. Intl. J. Productivity Qual. Manage., 19: 387-407.

Hill, J.F., C. Morris and R. Gabriel, 2007. An approach to the dynamic detection of outliers in electronics production. Intl. J. Prod. Res., 45: 765-778.

Joglekar, A.M., 2003. Statistical Methods for Six Sigma: In $\mathrm{R} \& \mathrm{D}$ and Manufacturing. John Wiley \& Sons, Hoboken, New Jersey, USA., Pages: 320.

Kaya, I. and C. Kahraman, 2008. On process capability analysis under fuzzy normal distribution. Proceedings of the 3rd International Conference on Intelligent System and Knowledge Engineering (ISKE'08) Vol. 1, November 17-19, 2008, IEEE, Xiamen, China, ISBN:978-1-4244-2196-1, pp: 424-428.

Li, Y., Y.M. Shi and L. Wang, 2007. Application of maximum likelihood estimation model in X-MR control charts. J. Phys. Sci., 11: 1-9.

Rezaie, K., B. Ostadi and M.R. Taghizadeh, 2006. Applications of process capability and process performance indices. J. Applied Sci., 6: 1186-1191.

Sun, J., S. Wang and Z. Fu, 2010. Process capability analysis and estimation scheme for autocorrelated data. J. Syst. Sci. Syst. Eng., 19: 105-127. 